\title{
The Ethics of Interspecies Performance: \\ Empathy beyond Analogy in Fevered Sleep's Sheep Pig Goat
}

\section{Laura Cull Ó Maoilearca}

$<$ INSERT FIGURE 1 HERE $>$

Figure 1. Sheep Pig Goat, Wellcome Collection and Fevered Sleep. Image by Ben Gilbert for Wellcome

\section{Introduction}

How can humans change the way they perceive nonhuman animals? What would it take to see animals differently and what role might empathy have in this process? If humans could perceive the world from the animals' point of view, would this change how humans perceive animals and, in turn, how they behave towards them? What role might performance play in allowing humans to occupy the animal's world as produced by its specific embodiment - its powers to affect and be affected that both differ from and overlap with human worlds (that are themselves differential)? And what happens if performance itself is seen from the animal's perspective? I begin with these questions in an attempt to mark out the fundamentally ethico-political stakes of engaging animals in performance: the urgent question of how performance might contribute to addressing anthropocentrism, speciesism, and the violence towards animal bodies such perspectives enable. In my ongoing work, I am interested in the capacity of performance to produce reciprocally transformative encounters - in which the affective worlds of both human and nonhuman bodies can be un-made and re-made, and wherein "animals are invited to other modes of being, other relationships, and new ways to inhabit the human world and to force human beings to address them differently." "These interests have led me to the project I will focus on here: Sheep Pig Goat (2017) by the UK-based performance company, Fevered Sleep - a project in which I played the role of "research advisor" when it was first staged in March 2017. I am also collaborating with the company to develop a new iteration of this performance which will be hosted at the Vet School at the University of Surrey in February 2020.

\footnotetext{
${ }^{1}$ Vinciane Despret, "Responding Bodies and Partial Affinities in Human-Animal Worlds," Theory, Culture \& Society, December 2013, Vol. 30 (7-8), 51-76, quote on 60.
} 
In this article, I consider Sheep Pig Goat alongside the work of foundational animal studies scholar and philosopher of science, Vinciane Despret - whose important book, What Would Animals Say if We Asked the Right Questions? (2016) was one text amongst many others that the company themselves read as part of the preparation for the project. In particular, I draw from Despret to explore multiple possible understandings of the notion of "interspecies empathy," noting that, for Fevered Sleep, a core aim of the project was to investigate how performance might "increase understanding of, and empathy towards nonhuman animals" (both their own as a company and those of the audiences who encounter their work $)^{2}$. Here, though, the mode of empathy I am reaching toward is not one that operates through analogy or identification, but an "embodied empathy" that operates as a mode of affective thinking alongside rather than "about" the animal, and as a performative encounter between human and nonhuman animals that produces both parties anew.

Both embodied empathy and attention have key roles to play in securing greater ethical consideration of nonhuman animals in relation to the production of knowledge. As Donna Haraway suggests, the etymology of seeing — from the Latin verb respecere, to look again — invites consideration of the relationship between attention and respect: to taking care in an ethical sense and the careful, iterative act of observation that does not judge on first impressions but considers others as worthy of $r e$-spect or, a second look. ${ }^{3}$ But this ethics of attention is not just about vision or sight and this is why performance might play a leading role in its investigation. Rather, as Amanda Boetzkes has argued, if "the fundamental ethical question" concerns "how we might develop a complex sensibility of and for non-human animals"4 or, if ethics is a matter of embodied behaviors improvised between actors in the uncertainty of specific contexts, then performance practices surely have much to contribute to the development of our understanding of what constitutes an interspecies ethics. Interspecies performance practice might be understood as a primary domain for the creation and investigation of what Traci Warkentin also describes as "an ethical praxis of paying attention." But whereas Warkentin's work foregrounds notions of attention primarily informed by phenomenology, my own engagement has been shaped by both Bergson and Deleuze, and in this

\footnotetext{
${ }^{2}$ David Harradine, David and Laura Cull Ó Maoilearca, “Interview with David Harradine," unpublished email interview, December 2018.

${ }^{3}$ Donna Haraway, When Species Meet (Minneapolis; London: University of Minnesota Press, 2013), 19. My thinking is informed not only by Haraway here, but by Matthew Goulish of the US-based company Every house has a door, who discussed the notion of re-spect as looking again in a lecture as part of the Abandoned Practices summer school in Prague in 2012.

${ }^{4}$ Amanda Boetzkes, “Art," in Turner, Lynn, Sellbach, Undine and Broglio, Ron (eds), The Edinburgh Companion to Animal Studies (Edinburgh: University of Edinburgh Press, 2018), quote on 79.

${ }^{5}$ Traci Warkentin, "Interspecies Etiquette: An Ethics of Paying Attention to Animals," Ethics and the Environment, Vol. 15, No. 1 (Spring 2010), 101-21.
} 
sense has a greater philosophical affinity with thinkers like Despret and Haraway who posit the primacy and constitutive nature of relation, rather than thinking in terms of things related (even when things are "themselves"). As Haraway puts it in When Species Meet: "The partners do not precede the meeting; species of all kinds, living and not, are consequent on a subject- and objectshaping dance of encounters."

The notion of the encounter, then, is fundamental not only ontologically but ethically. It is also the name that Fevered Sleep gave to the meetings between the improvising human performers and the sheep, pigs, and goats that form the central interspecies conversation of their project. Famously, for Deleuze, the "encounter" signals an event of non-recognition: a becoming of embodied thought with its "outside" as distinct from our tendency to engage with other worlds and lives through habitual modes of representation and pre-existing ideas (or "images of thought"). ${ }^{7} \mathrm{~A}$ key issue raised by Sheep Pig Goat is the barriers or blockages that are presented to encounters, or, more precisely, greater degrees of co-constitutive relation, particularly on the "human" side whether in terms of our tendencies to infantilize, sentimentalize, or anthropomorphize non-humans (though this article will also touch on a more positive or reciprocal conception of anthropomorphism in due course).

Recent years have seen an exciting surge of new scholarship and practice in interspecies performance. Moving away from using nonhuman animals in theatre and performance as metaphors for human concerns or as aesthetic short-cuts to a certain reality effect, contemporary interspecies performance research investigates, for example, to what extent performance might be something that humans make for nonhuman animal audiences, allowing humans to see the world from the animals' point of view. But what can performance offer to the understanding and practice of an ethical approach to knowing nonhuman animals? What constitutes an ethical way of knowing nonhuman animals and how can it be practiced in and as interspecies performance?

Fevered Sleep's Sheep Pig Goat offers two examples of how this ethical way of knowing might be performed. Firstly, the company's use of improvisation as an open-ended form of embodied and nonverbal questioning potentially allows the nonhuman animals to transform the human dancers and musicians understanding of performance itself. I draw parallels here between this idea and Despret's call to researchers to allow animals greater degrees of agency in the production of knowledge about them: to consider what animals would say if they were asked the

\footnotetext{
${ }^{6}$ Haraway, When Species Meet, 4.

${ }^{7}$ Gilles Deleuze, Difference and Repetition, translated by Paul Patton (London: The Athlone Press, 1994).
} 
questions that matter to them, rather than those that seem to matter from the human point of view. Secondly, their project engages with a form of embodied empathy: understood as a felt knowledge of the differential continuity between humans and nonhumans, rather than as an empathy through analogy that operates through a one-way anthropomorphic projection. Again, I turn to Despret to make links between the role of bodily knowledge in performance practices and the fieldwork of ethologists. In approaching the project in this way, I do not mean to hold up the first iteration of Sheep Pig Goat as some sort of ethical ideal—something that the company themselves would be the first to question and challenge. Rather, I foreground this project in all its ethical complexity because the question of the ethics of human knowledge of and co-existence with nonhuman animals is fundamental to Fevered Sleep's work and indeed a distinctive feature of the new forms of interspecies performance emerging today.

Throughout the essay I return to the idea of a reciprocally transformative interspecies encounter in contrast to the problem of inclusion by analogy or resemblance: wherein a concept, category or domain (whether "performance," "empathy," "knowledge," or the domain of equality or rights itself) is ostensibly extended to include nonhuman animals but only by a gesture of appropriation of the other into the same, rather than the transformation of the category itself through the encounter with the other. For example, critics have already argued that it is not enough to merely quantitatively increase the domain of contemporary morality in order to include a greater number of individuals - as animal rights advocate Peter Singer's "expanding circle" model seems to propose. ${ }^{8}$ Rather, we need new ethical models that do not rely on principles of resemblance: where nonhuman animals are afforded rights only to the extent that they can be asserted to be "just like us." There is a double-bind to this scenario: one in which humans are torn between the welfare benefits likely associated with the extension of legal rights to nonhumans, but at the same time skeptical of their underlying logic which reinforces rather than challenges the presumed moral superiority of humans. This is a double-bind that requires us to think difference and continuity, heterogeneity and commonality together, rather than as mutually exclusive.

Presumption of ontological difference leads to the justification of different moral treatment. And yet, in the case of nonhuman animals (and other oppressed groups), there is also the phenomenon of shifting goal posts. That is, humans' need to assert their moral privilege tends to mean that as soon as cross-species continuity is demonstrated with respect to a given quality or competency (like reason, emotion or language), the lines are redrawn between the nonhuman

\footnotetext{
${ }^{8}$ Peter Singer, The Expanding Circle: Ethics, Evolution, and Moral Progress (Princeton: Princeton University Press, 1981).
} 
version of the quality and its "properly" human counterpart. In this context, those seeking to improve the ethical consideration shown to nonhuman animals have the choice between playing the game of proof (the rules of which will continue to change) or making the case for equality on the grounds of differential continuity (or a continuum of difference): the shared yet heterogeneous nature of human and nonhuman animal worlds. ${ }^{9}$ My concern here, and more broadly, is in what making the case for interspecies equality might involve, insofar as it may not be most effectively considered as entirely a matter of logical argument so much as an embodied act. As I'll try to suggest in what follows, Fevered Sleep's Sheep Pig Goat offers an instance of how interspecies performance can solicit affective shifts in embodied perception that might also lead to behavioral change.

\section{Fevered Sleep's Sheep Pig Goat}

In 2017, I was a research advisor on Sheep Pig Goat, a project by Fevered Sleep, commissioned by the Wellcome Collection as part of their year-long Making Nature program. The project explored the relationship between perception and knowledge in human-animal relationships, along with all the attendant issues of mastery, anthropomorphism, and anthropocentrism inevitably raised by the human production of knowledge about animals. Described by the company as a "creative research studio," Sheep Pig Goat involved a week-long public presentation of "a series of improvised encounters between human performers and animal spectators:" specifically, sheep, pigs, and goats. Originally, the idea was to make a performance for an animal audience staged in the galleries at the Wellcome, an idea that echoes projects like Laurie Anderson's Concert for Dogs (2010) or even more historic examples like the orchestral concert that was put on for the "captive audience" of a pair of Indian elephants in the Jardin des Plantes in eighteenth-century Paris. ${ }^{10}$ The company gradually moved away from this idea, however, in favor of plans for a project which would offer human visitors what co-director David Harradine describes as a space in which to "properly, respectfully and carefully observe animals watching a performance and reflect and report back on what they've seen, whether it's the body language of a pig or a goat." "For Harradine: "humans do a really bad job of paying attention," and so the project was conceived as giving both the company

\footnotetext{
${ }^{9}$ I discuss the idea of a non-oppositional relationship between difference and continuity in more philosophical detail at the end of my book Theatres of Immanence (London; New York: Palgrave, 2013), see 234-38.

${ }^{10}$ Walter Putnam, "Captive Audiences: A Concert for the Elephants in the Jardin des Plantes," TDR: The Drama Review, Vol. 51, No. 1, Spring 2007, 154-60

${ }^{11}$ David Harradine quoted in Lyn Gardner, "Sheep Pig Goat: Theatre for an Audience of Animals," The Guardian, Theatre Blog, first published Wednesday 15 March 2017, available at

https:/www.theguardian.com/stage/theatreblog/2017/mar/15/sheep-pig-goat-theatre-show-for-animals
} 
and a wider public the opportunity to attend to animals, as themselves, engaged in processes of attending, rather than as the mere objects of human observation.

In particular, Harradine implies, humans have become highly selective in our perception of human-animal commonality not least, perhaps, on account of the demanding new ethical responsibilities such a perception might raise. In this sense, it may be less a matter of how much attention humans pay to animals, and more about how attending is performed (or how attention itself is understood). The kind of attention that Sheep Pig Goat invites is not attention conventionally understood as an immobilizing gaze or a process of selection and exclusion. Rather, it is an expanded, bodily attention to animals that differs from the everyday insofar as it does not "turn away from what it has a material interest in not seeing." 12 As Fevered Sleep co-director Sam Butler notes, it is not that humans are poor at attending to animals per se, but that they attend to some animals more closely than others in order to suit their own needs. ${ }^{13}$

In order to go at least some way to allow the performance-based research to speak for itself, I would now like to invite readers to watch the company's film of the project first before reading on.

\section{$<$ EMBED SHEEP PIG GOAT FILM HERE $>$}

Founded in 1996 by Harradine and Butler, Fevered Sleep has created over thirty different projects of which Sheep Pig Goat is not the first to engage with animality. As the company describe, Sheep Pig Goat came "on the back of a number of projects where we've found ourselves in the presence of animals or we've somehow wanted their presence in our work." ${ }^{14}$ An Infinite Line: Brighton (2008), for instance, was "an exploration of and response to the quality of natural light in Brighton," a performance which featured a white spotted stallion, Phoenix, owned by the same handlers who provided the animals for Sheep Pig Goat. ${ }^{15}$ But whilst the live horse who appeared in

\footnotetext{
${ }^{12}$ Henri Bergson, "The Perception of Change" in Henri Bergson: Key Writings, edited by Keith Ansell Pearson and John Mullarkey (London; New York: Bloomsbury, 2014), 303-27, quote on 309.

${ }^{13}$ Butler notes: "There's a hierarchy around which animals are welcome in our houses and onto our laps and into our beds sometimes, and the ones that we feel an urgency around taking care of and really observing what their needs are and drawing comfort from, and so that relationship serves us, but because it serves us we therefore care for them; and then there are the other animals that we have a really close relationship with but for other reasons, and that is the other need that we have for them which is to do with eating meat or the desire I should say, to eat them. And so we have a relationship with them in different ways, or maybe most of us don't have a relationship with them and that's the point" Sam Butler quoted in Fevered Sleep and Laura Cull Ó Maoilearca, "On Sheep Pig Goat: An Interview with Fevered Sleep," unpublished interview transcript, recorded February 7, 2019, edited version available as a podcast at: https://soundcloud.com/laura-cull-o-maoilearca/on-sheep-pig-goat-an-interview-with-fevered-sleep

${ }^{14}$ David Harradine, quoted in Fevered Sleep and Laura Cull Ó Maoilearca, "On Sheep Pig Goat: An Interview with Fevered Sleep."

${ }^{15}$ Harradine, David, Invisible Things: Documentation from a Devising Process, created in collaboration with Synne Behrndt and Valle Walkley (London: Fevered Sleep, 2011).
} 
this early work was arguably there as a kind of stand-in, a metaphor for the extraordinary indifference of the natural phenomena that the performance hoped to be about, the animals in Sheep Pig Goat move well beyond operating as mere vehicles for human expression. In turn, the project could also be situated alongside projects such as The Weather Factory (2010) and It's the Skin You're Living In (2012), which, as Lisa Woynarski has outlined, "highlight and critique our relationship to ecological conditions such as global climate change" and "gesture towards a nonanthropocentric performance aesthetic." ${ }^{\prime 16}$ The latter, for example, is a multi-format film project that features "a man dressed like... a polar bear" as he undertakes "a fragmented journey from the northern reaches of Europe, through Scotland, to the south of the UK." 17

As documented in the film, the first iteration of Sheep Pig Goat took place in March 2017, in a London warehouse trying to be as much like a barn as possible. The animals involved were chosen for their familiarity with human contact and were transported to the site from a farm in Wales, along with their handlers, who supervised all aspects of the animals' participation in the project and were present for all of the encounters with the principle function of attending to the animals' welfare. They included three sheep, two female Tamworth pigs (who are kept by their handlers for breeding) and a group of four rescued goats (all adolescent males). ${ }^{18}$ The human performers included a bass clarinetist, a viola player, a double bassist, a singer, and two contemporary dancers, all of whom the directors described as offering a kind of "toolbox" for the unknown requirements of the work to come: all expert improvisers, all expert non-verbal conversationalists, valued by the directors for their heightened competencies in relational attentiveness.

It has become commonplace to define a performance practice as "research" according to, amongst other things, the criteria of "questioning." Sheep Pig Goat does exactly this: both in terms of explicit research questions expressed in human verbal language, but also in the nonverbal and bodily forms of questioning it performs. Situated in a professional arts rather than an academic context, pre-show framing nevertheless took great care to manage audience expectations by making clear that what they were coming to see was a public staging of the research process itself, not an entertaining show or finished piece. The project framed itself as a use of performance to investigate a series of questions, including: "how well do humans see animals as they really are - not as we tell ourselves they are?;" and "what do animals perceive, when they perceive us?" The vexed question

\footnotetext{
${ }^{16}$ Lisa Woynarski, 'A House of Weather and a Polar Bear Costume', Performance Research, 20:2 (2015), 24-32, quote on 24.

${ }^{17}$ Fevered Sleep website, available at http://www.feveredsleep.co.uk/films/its-the-skin-youre-living-in/

${ }^{18}$ None of the animals involved in the project were destined for slaughter for human consumption.
} 
of anthropomorphism and to what extent we can know animals "as they really are" is something that I will return to. But for now, I want to emphasize the ways in which questions were a key part of how the encounters were structured. For Harradine, his and Butler's role in the project as codirectors was: "to create frameworks for the encounters, and to set tasks or targets for the performers, in an open-ended, non-directed way - through questions: What happens if...? Can you see how...? Is there any...? Could you...?"19 But then ultimately, and crucially, he suggests that: "It is the animals who direct us to 'direct' the performers." ${ }^{20}$ In this scenario, then, it is not just the artist-researcher who might be posing the questions that guide the research. Rather, we also need to consider what questions the animals themselves might have been posing; what questions did the sheep, pigs, and goats have about the behavior of these creatures with whom they found themselves sharing space and time? If current conventions mean that Sheep Pig Goat can be recognized as research because it asks questions, then the reason it is research that matters is because it is an exercise in trying to ask animals the right questions - to ask them the questions that allow them to speak, rather than the questions that silence or predetermine answers in advance, circularly. Not, yes/no questions: "Can animals perform? Can a goat dance? Are animals capable of the kinds of deliberate, conscious, chosen activity that would allow us to grant them the status of genuine performers?" But "and-and" questions: "How can we hear the animals' own questions?" and "how might animals change our very idea of questioning itself?" In this sense, this project is not a "use" or application of performance to animal research, but a kind of animalizing of both performance and research.

This questioning also takes place in and as the improvisational practices of the participating dancers and musicians. Naturally, the performers began with what they knew: techniques of structured play, call and response, embodied invitation, and listening. Improvisation offers rich resources for the enactment of ethical approaches to knowledge-production of nonhuman animals: allowing performers to hold themselves in states of heightened openness and responsiveness to the continuity and difference of other bodies, and employing strategies to approach creation (of movement or sound) as a fundamentally relational process emerging from unpredictable qualities of specific encounters rather than from individual authorial intention. However, even if improvisation processes like contact improvisation in dance and free improvisation in music are ostensibly concerned with novelty and "detraining," 21 they are also matters of technique and expertise: practices in which performers can find themselves settling into habits or styles as much as in other

\footnotetext{
${ }^{19}$ David Harradine, Unpublished correspondence with the author, 2018.

${ }^{20}$ Ibid.

${ }^{21}$ Steve Paxton quoted in Bojana Cvejić, Choreographing Problems: Expressive Concepts in European Contemporary Dance and Performance (London; New York: Palgrave, 2015), 136-7.
} 
modes of creative production. No matter how much Sheep Pig Goat had been set up as a "research studio" rather than a show, both the performers and the directors experienced some degree of pressure to perform according to stereotypical ideas of what counts as aesthetically pleasing or interesting behavior from a human point of view; their actions were initially shaped by a variously conscious awareness of the possible expectations of the human audience. This is the first destabilizing demand on the performers. In post-Encounter discussions, dancer Kip Johnson spoke about the shift between encountering his own ego in performance in the moment of internally evaluating his own movements to the dissolution of these values in the attempt to see himself from the animals' point of view. ${ }^{22}$ As I will return to later, there is then a second demand: that the action is not about performing "for" either the human or nonhuman animal audience according to existing ideas of what that act involves, but a sharing of the modes of action that might emerge in and as a more reciprocally transformative encounter. Performance does not precede but is produced by the encounter; dancer and pig co-create each other.

So, what happened during Sheep Pig Goat? "Very little happened actually," Butler says ${ }^{23}$. And she is right: there was something of the self-reflexive humor of failure of Marcus Coates's work here too; a wry smile as humans catch a glimpse of their own desperation for contact with an other who appears more interested in what there might be to eat, and in her fellow pig, than with anything a human might be doing. ${ }^{24}$ The animals in Sheep Pig Goat were invited to be observers of the human performers on their own terms: an invitation which they often appeared to take up precisely by largely ignoring them. But if from one perspective "very little happened," it is also that a lot happened. And indeed, it is because such a multiplicity of happenings took place, that no single response has the power to sanction the meaning of the event as a whole. When we ask, "What happened?" the response must take the form of an addition rather than a reduction. And-and.

\section{$<$ INSERT FIGURE 2 HERE $>$}

Figure 2. Sheep Pig Goat, Wellcome Collection and Fevered Sleep. Image by Ben Gilbert for Wellcome

\footnotetext{
${ }^{22}$ Kip Johnson reflected: "I think I am definitely learning that I have been conditioned to be affected, or wanting to please the people watching. I'm realizing quite how deeply embedded that is in me." See Kip Johnson, "Sheep Pig Goat Conversation - 11th December 2017," unpublished transcript of conversation between the artistic directors of Fevered Sleep and their performers who were part of Sheep Pig Goat. In future, the transcript will be publicly available in the Sheep Pig Goat archive held by the Wellcome Collection in London, UK.

${ }^{23}$ Sam Butler, unpublished remarks during Interspecies Performance: a workshop held at the University of Surrey in May 2018.

${ }^{24}$ Here, I am thinking of works by Coates such as the photograph, Goshawk (Self-Portrait) (1999) and the video work, Sparrow Hawk Bait (1999) which I discuss in Theatres of Immanence.
} 
What happened? Sheep Pig Goat was a demonstration of performance's epistemic force, a project that foregrounds performance as a mode of inquiry. But it was also a project from which the directors emerged speaking not of a contribution to knowledge but of an "abyss of ignorance." 25 It was a site of learning but it was also one of unlearning. Although, perhaps, having exited the paradigm of mastery, there is no reason why research might not be defined — as Despret suggestsas aiming to make the world more rather than less strange to us. From this perspective, Sheep Pig Goat appears as one way to respond to Despret's call "to learn to encounter animals as if they were strangers, so as to unlearn all of the idiotic assumptions that have been made about them." ${ }^{26}$ Indeed, as I sat in the encounters, I thought: If I sit here for long enough, perhaps I can unlearn the subtractive perception that allows me to see "the identity of animals as reducible to species membership." ${ }^{27}$ Perhaps I can learn to see this sheep, not $a$ sheep. And I thought: Perhaps if a certain kind of scientist sat here for long enough she might unlearn to see animals as limited to reactions, and in so doing create the possibility that animals might surprise the researcher who asks questions of them, breaking the circle of only encountering what extant knowledge has already predicted. $^{28}$

What happened? There is the difference between what happened to/for the performers who were there with the animals every day, and what happened for the visitors who, for the most part, only observed a single encounter. In this context, for instance, the singer described what was for her "a moment of sheer accomplishment" likely unnoticed by most of the visitors when the sheep "were comfortable enough to turn away while we were making sounds... that was so significant."29

What happened? A radical indeterminacy that functioned not just as a screen for anthropocentric projections (moving unilaterally from us to them), but as a site of a two-way movement. There were multiple knowledges projected onto the animal; at times, a given voice intervened to put an end to doubt. One of the handlers says to a dancer: "The pig is making that noise, because she doesn't like you moving in between her and the other pig. She's barking because you're getting too close." But something moved in the other direction too. Such moments felt like a kind of progress. As potential markers of appearance rather than the animals' indifference to the

\footnotetext{
25 David Harradine, unpublished remarks during Interspecies Performance, May 2018.

${ }^{26}$ Vinciane Despret, What Would Animals Say If We Asked the Right Questions? translated by Brett Buchanan, (Minneapolis; London: University of Minnesota Press, 2016), 161.

${ }^{27}$ Ibid., 2 .

${ }^{28}$ Ibid., 39.

${ }^{29}$ Sterre Maier, "Sheep Pig Goat Conversation - 11th December 2017," unpublished transcript.
} 
performers but also as (de-romanticizing) reminders that encounters hold the possibility of conflict, such that the dance that follows becomes a choreography of negotiation. How close is too close? ${ }^{30}$

\section{$<$ INSERT FIGURE 3 HERE $>$}

Figure 3. Sheep Pig Goat, Wellcome Collection and Fevered Sleep. Image by Ben Gilbert for Wellcome

\subsection{Performance for animal audiences}

In foregrounding the notion of the nonhuman as the bearer of attention, Sheep Pig Goat could be seen in the context of a wider set of practices concerned to explore the idea of making performance for nonhuman animals as spectators or audiences: from Anderson's Concert for Dogs, Tuija Kokkonen's A Performance with an Ocean View (with a Dog/for a Dog) - II Memo of Time (2008), to the ongoing Performances for Pets (2014) project in which artists Krõõt Juurak and Alex Bailey "present bespoke performances for pets in their familiar environment." ${ }^{31}$ As the artists note: Animals have been entertaining humans throughout the ages in circuses and zoos, entertainment by pets has overtaken the Internet, every pet is in a sense a performer for humans. We wanted to reverse the roles and offer the animals the position of the viewer. When it comes to performing and being interesting pets are superior to us in several ways. When a pet comes on stage, for example they instantly capture everyone's attention. So the inspiration for the performance was really a "what if" we reversed the roles for a moment. Making this performance has enabled us to see the world from the pets' point of view and we are hoping to learn from them. And we also wanted to expand our audience across species. ${ }^{32}$

In the case of Juurak and Bailey, the transformative work is less focussed on the humans living alongside the "pets" and more focussed on their own perception as performance-makers: often using imitation as the starting point for embodied empathy and becoming with their particular animal audiences. This is no easy identification though. Given the different world their sensory powers performatively produce, it seems likely, as Jessica Ulrich suggests, that the cats and dogs are experiencing the performances by Juurak and Bailey "in many ways that are inaccessible for

\footnotetext{
${ }^{30}$ Despret, What Would Animals Say, 17.

${ }^{31}$ Juurak and Bailey's use of the term "pet" here, rather than Haraway's now widely used term "companion species," might be jarring for some. However, as the description here and interviews elsewhere suggest, the artists' practice very much aligns with the notion of domestication as reciprocal transformation that one finds in Haraway, rather than reasserting any species hierarchy that might be construed as intrinsic to the notion of animals as "pets."

${ }^{32}$ Krõõt Juurak and Alex Bailey, "Q\&A," available at http://www.performancesforpets.net/info.
} 
humans." ${ }^{, 33}$ Indeed, when asked in an interview about what "the most eventful thing" was that had happened during the Performance for Pets project, the artists politely decline to answer. Polite, that is, in Despret's sense insofar as they seek to acknowledge that what counts as an "event" will differ amongst species. They add instead: "We feel it would be unfair to point out some moments that seemed like events to us. Only the pets will know of the most eventful moments for them."

Sheep Pig Goat likewise calls to mind the broader traditions of "art for animals" as discussed by art historians like Ulrich and Matthew Fuller, which take us back to works such as Wolf Kahlen's 1977 scent-based exhibition for dogs Dog Territory, or to new works in interspecies film such as Rachel Mayeri's Primate Cinema: Apes as Family (2011). In the case of Kahlen's piece, Ulrich emphasises the new demands that an animal audience might make on the skills of the human artist, noting that "Scents are doubtless more interesting to dogs than paintings. But this means in this case that an amateur creates for an expert audience." 35 Of course, the same applies for the researcher: in my case, a near complete sense of incompetence to account for the experience of a key set of participants in the performance I am seeking to analyse. Interspecies performance demands new competencies of us all that cannot be developed overnight.

The starting point for many of these works is a simultaneously playful and serious interest in the ethico-political implications of a reversal of roles wherein the nonhuman animals who have so often been objects of the human gaze, including for the purposes of entertainment, are acknowledged as subjects of their own perspective: specifically as neglected spectators of aesthetic events. But there is clearly no necessary emancipatory dimension to the reversal in itself: no guarantee of any revaluation of values through the sheer act of positioning of animals as audiences. Indeed, as Ulrich discusses with respect to Annika Kahrs' 2013 piece Playing to the Birds, such reversals can serve to reinforce anthropocentrism. For her part, Ulrich argues that "Art that confronts animals with human paintings or plays human music to animals stays deeply anthropocentric and clings to a value system animals usually cannot relate to. ${ }^{\text {}}{ }^{36}$ In Kahrs' piece, for instance, Franz Liszt's Legend Number 1. Sermon to the birds by Saint Francis of Assisi (1863) is performed to an audience of caged birds in a concert hall. As Ulrich suggests, the emphasis is very much on "the musical preaching of an all too human convention of music," rather than any

\footnotetext{
${ }^{33}$ Jessica Ulrich, "Art for Animal Audiences," pesented at Sophiensaele, Berlin on the occasion of Animal Forms \& Formulas -On the human-animal-relation in contemporary performance, October 1, 2017, available at http://www.performancesforpets.net/text; accessed June 1, 2019.

${ }^{34}$ Juurak and Bailey, "Q\&A."

${ }^{35}$ Ulrich, "Art for Animal Audiences."

${ }^{36}$ Ibid.
} 
responsiveness to the birds' themselves who have no choice (it seems) but to listen from their confinement. $^{37}$

If there has been an increase in artists making work for animal audiences, then there has simultaneously been a growth of interest in the possibility of using the arts to give humans the chance to experience what is framed as "the animal's point of view," including by animal rights organizations banking on the capacity of empathy to create behavioral change (despite others concerns for its long-term political efficacy). For example, PETA have launched a series of VR based works including I, Chicken (2014), a VR experience which they claim "allows people to view life from a chicken's perspective before being sent to slaughter," and I, Orca (2015), also specifically sold as an "empathy-building" project, which "uses wireless Google virtual reality goggles to immerse participants in a world where they can swim freely in the ocean with their orca family." ${ }^{38}$ A more formally interesting project from this perspective is Cleary Connolly's MetaPerceptual Helmets (2015): a series of head pieces designed to help human museum visitors "to see the world the way hammerhead sharks, giraffes, horses and chameleons see it." ${ }^{39}$ Inspired by research undertaken at the turn of the twentieth century by psychologist George M. Stratton, the use of mirrors inside the helmets gives at least some kind of embodied experience of the relative nature of human perception. According to the artists: "The hammerhead helmet lets the wearer see 360 degrees except for a blind spot right in the center of its vision, which is resolved by swinging the head from side to side like hammerheads do. The chameleon helmet has independently-rotational eyes like the lizard which allow the user to look at two objects at the same time. The giraffe helmet puts the eyes above the helmet while the horse helmet lets the user see what's coming from behind." ${ }^{40}$ But whilst both of these projects arguably place an undue emphasis on vision and on the idea of animal perception as simply a different way of seeing (or point of view on) an objective world, Despret's work emphasizes the notion of the animal's point of view as a world. Drawing from von Uexküll's well-known notion of the Umwelt, Despret suggests that it is not that the animal perceives "this" world differently, but performatively produces and inhabits a different (albeit to varying degrees parallel, overlapping, or "associated") world on the grounds of its particular powers of perception and affection. ${ }^{41}$ In turn, this move from thinking in terms of perspective on a world to affective worlding indicates an important role for embodied empathy as a mode of felt knowledge (and unknowing) in relation to nonhuman animals.

\footnotetext{
${ }^{37}$ Ibid.

${ }^{38}$ PETA website, available at https://www.peta.org/about-peta/milestones/

${ }^{39}$ See the artists' website for further information: http://www.connolly-cleary.com/Home/helmets

${ }^{40}$ Paul Seaburn, "Helmets Help Humans See Like Hammerheads and Horses," Mysterious Universe, published January 9, 2015, available at https://mysteriousuniverse.org/2015/01/helmets-help-humans-see-like-hammerheads-and-horses/

${ }^{41}$ Despret, What Would Animals Say, 161-7.
} 


\subsection{On (embodied) empathy}

The question of the potential role of empathy in the production of knowledge about nonhuman animals is a long and hotly debated subject, not least on account of the problems associated with "empathy by identification," or what Wendy Rose calls, "the tourism of the soul."42 In this context, Despret's work contributes a valuable inventory of some of the diverse range of "empathic postures" enacted by animal scientists in the course of their research, in ways that, I'd argue, provide a productive cross-disciplinary context for a consideration of Sheep Pig Goat (as well as pointing toward potential lines of future enquiry into ethological fieldwork $a s$ performance). ${ }^{43}$ Cognitive ethologist and canine behavior expert, Mark Bekoff, for instance, claims that he "can feel what animals are feeling," and that, on account of mirror neurons, "this emotional empathy seems to be innate." " In contrast, Despret argues for an "empathy without pathos" renowned animal scientist and autistic spokesperson, Temple Grandin, who does not claim that her own feelings allow her to know what animals feel, but that she thinks like an animal: visually, and in details. Grandin suggests that the world appears to her (as it does to cows, she claims) "as a swirling mass of tiny details" such that she is in a position to provide other humans (like slaughterhouse designers) with access to how the world appears to animals, whose behavior, particularly their fear, otherwise remains mysterious (troublesome, expensive...) to them. ${ }^{46}$ Notoriously, Grandin's practice involves using her own body to perform a literalization or embodied enactment of the empathic gesture. For her, as Despret outlines, one cannot understand animals " "unless you put yourself in their place - literally in their place. You have to go where the animal goes, and do what the animal does' in order to see what it sees and understand what scares it." 47

For her part, Despret insists on multiple understandings of empathy in animal contextsbeyond a conventional understanding of empathy as feeling what the animal feels - as well as a differentiation between the purposes and approaches of a range of empathetic practices (from Grandin and Bekoff's, to those of female primatologists like Shirley Strum and Barbara Smuts). In

\footnotetext{
${ }^{42}$ Wendy Rose quoted in Donna Haraway, Simians, Cyborgs and Women: The Reinvention of Nature (London: Free Association Books, 1991), 113.

${ }^{43}$ Vinciane Despret 'Responding Bodies and Partial Affinities in Human-Animal Worlds', Theory, Culture \& Society, December 2013, Vol. 30 (7-8), 51-76, quote on 58.

${ }^{44}$ Marc Bekoff, The Emotional Lives of Animals (Novato, CA: New World Library, 2007), 128.

${ }^{45}$ Despret, "Responding Bodies," 59.

${ }^{46}$ Ibid., 58.

${ }^{47}$ Ibid., 59.
} 
her work on the interactions between the human bodies of scientists and the animals they seek to observe and come to know through fieldwork in the context of ethological research, Despret foregrounds the notion of "embodied empathy:" "a concept which describes feeling/seeing/thinking bodies that undo and redo each other, reciprocally though not symmetrically, as partial perspectives that attune themselves to each other." ${ }^{, 48}$ Notions of embodied empathy provide important resources for thinking and practicing empathy beyond analogy or resemblance. In particular Despret's account of embodied empathy as a process of bodily questioning supports my own sense of the function of improvisation in Sheep Pig Goat.

For Despret, interspecies empathy does not imply experiencing with one's own body what the nonhuman animal experiences, "but rather creat[es] the possibilities of an embodied communication." ${ }^{49}$ Specifically, Despret talks about empathy as a "tool that attunes bodies," but one that needs to be reinvented or redefined in each new affective context. ${ }^{50}$ This embodied empathy, she suggests, might be understood as "the process by which one delegates to one's body a question, or a problem, that matters and that involves other beings' bodies. Bodies are articulating, and become articulated, in the asking and in its responses. ${ }^{, 51}$ Elsewhere she specifically evokes this as a process of learning to think with animals, rather than about them as objects — processes which may or may not proceed through methods of imitation or seeking to act "as if" one were that animal.

Furthermore, the unlearning and active forgetting of presumed knowledge is an important feature of this methodology. That is, for Despret, interspecies empathy involves both an unlearning of how to think according to pre-existing assumptions (in which knowledge about the animal is merely applied to it), and the experimental production of new modes of thought alongside animals, undertaken particularly - though not exclusively — through the body. ${ }^{52}$ Conventionally anthropomorphism is understood as an intellectual, voluntary projection of the image of the human onto the animal, according to a kind of fantasy identification. In contrast, both these perspectives suggest that who humans are as biological beings_-including any images of themselves as social, empathetic beings-

\footnotetext{
${ }^{48}$ Ibid., 51.

${ }^{49}$ Ibid.

${ }^{50}$ Ibid., 71.

${ }^{51}$ Ibid., 70.

${ }^{52}$ For Despret, it is not that there is one way or a single approach that would allow us to see the world from an animal's perspective. In this respect, highlighting the body of the researcher is not the "answer" necessarily. "One may indeed construct a perspective without involving the body. The perspective may be drawn (perhaps only partially) solely from a mental process, as the naturalist and theorist of the Umwelt theory, Jakob Von Uexküll, did" Despret, ibid. 55. In terms of this dual process of unlearning in order to learn, we might also see analogies between approaches to unlearning in performance and those highlighted by ethologists like Shirley Strum who remarks of her efforts to think with baboons: "I made a determined effort to forget everything I knew about how baboons are supposed to behave. Instead, I tried to let the baboons themselves 'tell' me what was important" Strum, Almost Human (New York: Random House; 1987), 30, emphasis added.
} 
-is underpinned by an already given mutuality, whether through communicating bodies or innate neurons.

\section{$<$ INSERT FIGURE 4 HERE $>$}

Figure 4. Sheep Pig Goat, Wellcome Collection and Fevered Sleep. Image by Ben Gilbert for Wellcome

Fevered Sleep's project — controversially for some (and in ways that were acknowledged as ethically problematic by the company themselves)_involved bringing the animals to us, rather than us going to them. The performers did not literally put themselves in the (usual) place of the farm animals per se; rather, the project transported the animals and performers to a new third place - a warehouse in Peckham, albeit one which (as already noted) the company described as trying to be as like a barn as possible. And yet, there was some bodily adjustment required for both human performers and audience: to the unusual chilly temperatures of the space, but also the requirement for the dancers, in particular, to move across floors often scattered not only in hay, but in the animals' urine and faeces (though without, I hasten to add, any opportunity for the animals' to reciprocally observe the human performers' or audience's bodily functions!).

In ethological fieldwork, Despret argues, the ideal is still "that the animals may follow their routine as if the human observer was not there. One is the observer, the other the observed." Fevered Sleep's Sheep Pig Goat, by contrast, draws attention to the animal as observer; or rather, to the reciprocity of observation in human-animal encounters, according to an expanded sense of the term "observation," the etymology of which signals not only acts of watching and looking, but also "heeding" or "attending to:" processes that might involve multiple sensory or affective modes. ${ }^{54}$ Indeed, given the variable numbers of bodies in the space of the encounters within Sheep Pig Goat (sometimes one dancer and two pigs; sometimes four goats and two musicians, plus the presence of the two co-directors, the audience), the network of observational processes is complex and multidirectional as humans and nonhuman animals conduct observations of one another. The etymology of observation also suggests links between what it is "to observe" and what it is "to keep safe" or "to protect", inviting consideration of attention as a form of care. For instance, at one moment, the older pig "looked out" for the younger, observing and vocally responding to the dancer who had

\footnotetext{
${ }^{53}$ Ibid., 53.

${ }^{54}$ As the film of the project emphasizes, the audience are not detached "observers" either, merely cognitively processing the encounters. Rather, we are part of the ongoing process of responsiveness - a source of stimulus for the animals (our sounds, smells) and they for us (laughter, disgust).
} 
appeared to her to have come too close to them, to intrude on their space. This was a movement that mattered from the animal's point of view.

In Sheep Pig Goat, the performers aimed to set themselves up as the observed as well as the observers; though not always successfully or noticeably so, from a human point of view. That is, as Butler suggested, the animals often did not seem that interested in looking at the performers; although of course they may have been observing them - observing their observers - and responding to them in other ways. Or, to put it another way that recalls the terms of An Infinite Line, it is not that the animals were totally indifferent, so much as differently interested. From the point of view of human expectations of performance, this unresponsiveness might have been located as a problem. If what was sought was a certain kind of contact, communication, or exchange, then seeming non-engagement from one party could be framed as a form of failure. And yet, one key outcome of this project was the way it allowed animals to mutate the criterion for "success," or transform our understanding of what success might look and feel like in this context (recalling, once more, the vocalist Sterre Maier's description of the sheep's turned backs as "a moment of sheer accomplishment"). ${ }^{55}$

\section{$<$ INSERT TWO IMAGES SIDE BY SIDE $>$ <LEFT: FIGURE 5. RIGHT: FIGURE 6>}

Figure 5. Men \& Girls Dance, Fevered Sleep. Image by Matthew Andrews

Figure 6. Sheep Pig Goat, Wellcome Collection and Fevered Sleep. Image by Ben Gilbert for Wellcome

\subsection{From performing for to becoming with}

So far, to contextualise Sheep Pig Goat, I have touched on Fevered Sleep's other work with animals as well as those of other practitioners engaged in making performances for animal audiences. However, it may be just as or even more productive to consider Sheep Pig Goat in the light of some of the company's other projects, such as the much acclaimed Men \& Girls Dance (2016), which does not involve animals, but has strong similarities with Sheep Pig Goat in other ways. That is, Sheep Pig Goat can be framed as an extension to the domain of the interspecies, of a long-standing

\footnotetext{
${ }^{55}$ Maier, "Sheep Pig Goat Conversation," no pagination.
} 
concern with the politics and ethics of relationality that the company has hitherto explored in terms of human encounters across age and gender divides. Men \& Girls Dance, in particular-a devised performance co-created by a group of professional male dancers and girls who dance for funcould be seen as informing Sheep Pig Goat for a range of reasons. Both begin with an apparently unequal pairing: of the adult and the child, of the human and the nonhuman. Both projects create a contrast between the representational over-determination of that relationship and the unpredictability or creative potential of lived encounters involving individuals. In the case of Men $\&$ Girls Dance, the company framed the project as responsive to a media context in which they felt narratives of sexual abuse and exploitation had come to have not only a disproportionate, but damaging bearing on the ways in which men and girls might relate to each other. In the case of Sheep Pig Goat, there is less of an emphasis on a single determining story; rather, the individual words that were on the wall inside the gathering space within the warehouse, and reappear in the short film, point towards the myriad categories, stereotypes, and stories that might serve to organise our perception of nonhumans preventing the more creative and reciprocally determining forms of encounter I invoked at the start.

In Fevered Sleep's previous works, there is a notable effort to pursue a consistency of process and "product" (or form); or rather, the sense is that the politics of the work lies very much in how it was made, and that this process remains visible in the form itself (in terms of the visibility of a specific mode of improvisation made possible through the use of task- and game-based techniques in Men \& Girls Dance, for instance). Though, for the company, one of the exposing features of Sheep Pig Goat as a project was the extent to which it opened the research process itself to a public audience, without the safety of more structured "content." That is, whilst Men \& Girls Dance is a "semi-choreographed, semi-improvised performance"-with aspects co-created anew in each locale and with each group of dancers the company work with—Sheep Pig Goat was entirely improvised for its duration ${ }^{56}$.

As noted earlier, Ulrich criticises the anthropocentrism of art works that force animals to listen to what humans value as "music." Does this criticism apply to Sheep Pig Goat? For their part, Fevered Sleep emphasize that the animals were invited to act as spectators "on their own terms," which might include choosing to leave the space of the encounters. Likewise, the nature of the musicians' performance was radically different from Kahrs' work insofar as it was fully improvised and ostensibly structured to be responsive to the sounds made by the animals themselves. However, the company have reflected on the ways in which the encounters changed over the course of the

\footnotetext{
${ }^{56}$ Fevered Sleep, “Men \& Girls Dance," available at https://www.cssd.ac.uk/content/men-girls-dance.
} 
week: becoming "more to do with being together rather than dancing or playing or singing for. 'How can you leave a trail of scent for this pig with your breath?' rather than 'can you see if this sheep will watch you dance?",57 Is this the beginning of how the animal animalizes performance? The performer is, still, performing for the animal, but in a context where performing no longer means "dancing or playing or singing" so much as leaving a trail of scent because her audience is a being who produces a world where smell means more than sound. Working towards a second iteration of the project, which will be held at the Vet School at the University of Surrey in the UK in 2020, one key difference in the company's approach might be a change in the "toolkit" they bring to the encounters. As David Harradine asks: "If pigs experience the world through scent and touch, what should we be bringing into the space to depart from that, rather than departing from our ideas of music and dance? If goats want to play with objects and to climb, how can we work with that? What would a sheep, or a horse, or a cow, 'want' us to explore with them?"58

\section{Conclusions: Differential continuity in interspecies encounters}

"Want" is in scare quotes above for fear of accusations of anthropomorphism in the attribution of agency and interests to nonhuman animals. Conventionally, anthropomorphism is something one is guilty of: perceived as a kind of stupidity or naïve way of thinking. As Lisa Jevbratt recounts, anthropomorphism is "a term uttered with disdain within both scientific and humanistic research communities. It is seen as error of sentimentality that makes (objective) research impossible. ${ }^{, 59}$ However, it is important to reclaim the concept of anthropomorphism from such pejorative and reductive understandings that reinforce assumptions that there are exceptionally human characteristics in the first place. In contrast, more recent work in animal studies and new materialist discourse has sought to reclaim the value of a kind of expanded anthropomorphism that exposes the indeterminate notion of the human to a mutation by animal modes of thought, contra its default categorization as “error.” In particular, John Mullarkey encourages thinking in terms of a distinction between the "half-anthropomorphism" of unilateral projection (which is usually understood to exhaust the concept per se) and a "complete anthropomorphism" of reciprocal mutation. ${ }^{60}$ Taken up in the context of performance, the former refers to the application of a standard humanist form of performance to the animal without any change to the concept itself. In

\footnotetext{
${ }^{57}$ David Harradine in Fevered Sleep and Laura Cull Ó Maoilearca, “On Sheep Pig Goat: An Interview with Fevered Sleep".

58 Ibid.

${ }^{59}$ Lisa Jevbratt, 'Interspecies Collaboration - Making Art Together with Nonhuman Animals', Interspecies Collaboration website, 2009, available at jevbratt.com/writing/jevbratt_interspecies_collaboration.pdf, 14.

${ }^{60}$ John Mullarkey, 'The Animal Line: On the Possibility of a "Laruellean” Non-Human Philosophy', Angelaki, 19:2 (2014), 113-29, quote on 119.
} 
the latter, a multilateral and "complete anthropomorphism" expands the meaning of performance in the event of interspecies encounter. As Mullarkey suggests, this latter form of perception is not a "way of seeing" but "a lived, bodily stance:" a kind of behavioral openness to what performance might become rather than measuring the unknown according to extant (human) standards. ${ }^{61}$

Likewise, the notion of interspecies empathy is by no means straightforwardly celebrated. It raises the charge (like empathy in general) of misguided identification and understanding and reinforcing an assumed capacity to access the minds of other animals or to adopt their viewpoints. In the particular case of animals, so the criticism goes, what is construed as interspecies empathy is in fact mere anthropomorphic projection; no feeling with the animal at all, only a one-way projection of my human feelings onto the animal or a misattribution. L.B. Cummings' emphasis on the two-way movement of empathy reconceived as dialogue (or "dialogic empathy") is important in refiguring empathy in performance as an on-going and dynamic process or encounter. ${ }^{62}$ For Cummings, dialogic empathy "does not confuse self with other or rely on analogies. In this kind of empathy, all subjects strive to engage one another as equals in an exchange, open to the possibility of new thoughts and feelings.",63

For his part, Harradine clearly places great store on both the epistemological and ethicopolitical value of embodied empathy and defends it against charges of anthropomorphism (or what Mullarkey would call "half-anthropomorphism"):

I do not empathise with non-humans because I project my human-ness onto them and feel for myself in return. With other mammals I feel empathy because I see deep anatomical, structural, evolutionary, genetic connections that make it possible for me to imagine - momentarily, fleetingly, horrifyingly - some version of the world from their point of view. Like a pig I am born in blood and pain. Like a pig I drank food from my mother's body. Like a pig I exist as myself and also as part of the social structure which makes me. Like a pig I have social relations, and I play these out through vocal communication and in complex relationships between individuals. Like a pig I experience fear and pain. To feel empathy is not anthropomorphic. It destabilises human exceptionalism in hugely important ways. ${ }^{64}$

\footnotetext{
${ }^{61}$ Ibid., 120.

${ }^{62}$ L.B. Cummings, Empathy as Dialogue in Theatre and Performance (London; New York: Palgrave, 2016$), 6$.

${ }^{63}$ Ibid., 8.

${ }^{64}$ David Harradine, Unpublished correspondence with the author, 2018.
} 
Such embodied challenges to human exceptionalism and the willingness to perceive continuities between humans and nonhuman animals remain key (contra what de Waal identifies as our tendency towards "anthropodenial") ${ }^{65}$ : that is, the genuine practice of an equality for animals or the real inclusion of animals within the ethical sphere must be understood beyond the model of an expanding circle. In other words, there is a problem if empathy relies on analogy or identification; if we can only empathize with animals to the extent that we perceive them to be like "us": as proven to be capable of thought and emotion according to pre-existing human definitions of those properties.

Of course, empathy itself continues to be used to shore up human exceptionalism-despite countless counter-arguments seeking to demonstrate non-human instances of empathetic behavior. As Cummings discusses, for many contemporary psychologists - as well as those cognitive neuroscientists who construe empathy as to some extent "innate" or "hard-wired"-_empathy is the path to our greatest potential humanity." ${ }^{, 66}$ Recent work in animal studies has produced countless accounts of ways in which nonhumans might not only be included in, but empowered to transform our concepts of what empathy is and who is capable of it. Moreover, there is a performative contradiction in denying empathy to others in the name of one's own greater empathy. The paradox is undone by seeing or attending to the animal's behavior as empathy (albeit in a different form): according to what philosophers might call a "leap of faith" or "open soul."67 This would be not a discovery of the same - the same capacity for empathy in the animal, for instance - but a discovery of what we might call a differential continuity: a kind of mutuality that is not reciprocated in kind but can nonetheless recognize a kinship in difference.

At the opening of this article I asked: What can performance contribute to our understanding and practice of an ethical approach to knowing nonhuman animals? What constitutes an ethical way of knowing nonhuman animals and how do we practice it? To conclude, I propose that, in the first instance, the ethical involves a kind of "epistemic justice,"

\footnotetext{
${ }^{65}$ Frans B. M. de Waal, "Anthropomorphism and Anthropodenial: Consistency in Our Thinking about Humans and Other Animals," Philosophical Topics, 27: 1 (1999), 255-280

${ }^{66}$ Cummings, Empathy as Dialogue, 4.

${ }^{67}$ The notion of the leap of faith comes from Kierkegaard and the open soul from Bergson. I have begun to draw some connections between the latter and the work of interspecies performance in a recent publication, see: Cull Ó Maoilearca, Laura, "Opening the Circle: Performance philosophy as an animal movement," Performance Research: On Reflection, 23:4 (2018), 399-401

${ }^{68}$ The term "epistemic justice" was coined by the British philosopher, Miranda Fricker in 2007 in her book Epistemic Iinjustice: Power and the Ethics of Knowing where it concerns the refusal to recognise an individual's capacity as a knower. Whilst most engagements with Fricker's concept are focussed on epistemic injustice towards humans, the idea has begun to be extended to nonhuman animals by researchers such as Rebecca Tuvel - the scholar at the center of the Hypatia transracialism controversy. See Rebecca Tuvel, Epistemic Injustice Expanded: A Feminist, Animal Studies
} 
"knowers" and as living beings who performatively produce and inhabit a point of view that constitutes a sensory and perceptual form of worldly knowledge, as much as those produced by humans. An ethical approach means confirming that animals have something to teach us about what knowledges are and how they are produced, rather than simply measuring animals according to any single standard of human knowledge. Secondly, an ethical mode of knowledge production involves the reciprocal and dialogic rather than the unilateral. If knowledge-making is forever in process and flux, then more ethical modes allow for multi-directional movement, rather than that which is imposed by some knowers onto others, or which erases the plurality of worldly knowledges by assimilating them into the category of "knowers" but without any qualitative change to the category itself.

Theatre and performance, especially in examples like Sheep Pig Goat, can be sites for intimate encounters with nonhuman animals that allow for new forms of interspecies communication. As Una Chaudhuri has argued, this might suggest that there is something special about performance in terms of forwarding our understanding of nonhuman animals. As an art focussed on embodied relationality, performance is particularly well equipped to explore non-verbal communication across the species barrier supposedly presented by animals" "lack" of language (or what has been construed as the human failure to sufficiently listen to and understand what nonhuman animals are already saying). ${ }^{69}$ And indeed, embodiment has been a key emphasis in this article, particularly in terms of distinguishing between the reciprocity of embodied empathy in contrast to models of empathy based on unilateral projection and identification. However, the duality of the performative process is important to bear in mind in balancing the enthusiasm and optimism for performance's power to create and inhabit new modes of relation to nonhuman animals with a reminder of its equal power to reinforce speciesist norms in and through its bodily practices. That is, "the animal" is "just" an idea-but no less real and with no less material effects on both minoritized human and nonhuman bodies for being such. The superimposed words that affectively punctuate the Sheep Pig Goat film enumerate exactly the kinds of ideas that script dominant bodily engagements with animals, from the explicitly violent to the well-meaning (but perhaps no less problematic as condescending, self-serving, othering). Fevered Sleep's project productively draws attention to this duality of performance by suggesting that improvisational techniques from the human arts of dance and music might provide one way to undo some of the speciesist and anthropocentric assumptions that live differently in our bodies.

Approach, Doctoral Thesis, 2014, available at: https://etd.library.vanderbilt.edu/available/etd-07102014161455/unrestricted/Tuvel.pdf

${ }^{69}$ Una Chaudhuri, “'Of All Nonsensical Things': Performance and Animal Life”, PMLA, 124:2 (2009), 520-25. 
Interspecies performance as a field must be understood not only in terms of the performing arts and social performance, but as encompassing a continuum of everyday activities and perceptual practices that involve varying degrees of repetition and unlearning of "restored behaviors" with respect to encounters with nonhumans. The production of subjectivity is always an interspecies performance regardless of the extent to which its human participants might acknowledge it as such. And yet, even this framing still only tells us one side of the story. To genuinely extend the field of performance to include nonhuman animals in meaningful qua transformative ways must also involve an openness to how bodies and ideas interact in and as forms of life where thinking, acting, and "point of view" take radically differing modalities than those afforded by the still humanist confines of the broad-spectrum.

$<$ INSERT FIGURE 7 HERE $>$

Figure 7. Sheep Pig Goat, Wellcome Collection and Fevered Sleep. Image by Ben Gilbert for Wellcome 